\title{
AN ASSESSMENT OF INTIMATE PARTNER FEMICIDE IN THE NAME OF HONOUR IN TURKEY: A RETROSPECTIVE EPIDEMIOLOGICAL STUDY
}

\author{
Naim Nur \\ Department of Public Health, School of Medicine, Sivas Cumhuriyet University, Sivas, Turkey
}

received: 28.2.2020;

revised: 17.8.2020;

accepted: 21.8 .2020

\begin{abstract}
SUMMARY
Background: Honour killing $(H K)$ is the most extreme form of domestic violence. Given the scarcity and reliability of data on the phenomenon, the present study focuses on the epidemiological pattern of HK in Turkey, where many cases of the HK are considered unreported or/and falsely described.

Subjects and methods: Data for this retrospective epidemiological study was collected through newspaper reports on intimate partner femicide (IPF) that published between January $1^{\text {st }} 2010$ and December $31^{\text {st }} 2015$. The proportion of HK was estimated according to independent variables by means of regression analysis.

Results: The femicide cases has increased during the study period. The proportion of the HK cases was $14 \%$. Logistic regression analysis showed that being at the younger ages (odds ratio, OR=2.0, $r=0.70, P<0.001)$ and using other methods such as strangulation, hanging, electrocution or poisoning were the factors associated with $H K(O R=1.8, r=0.60, P=0.004)$.

Conclusions: Given the continued increase in the rate of the IPF cases in Turkey, where HK related information is scarce, newspaper reports can be a good monitoring tool. Data collection and monitoring systems are crucial to find the best effective prevention strategies, particularly for HK. Policies to reduce the HK cases should be including support to women, especially at the younger ages.
\end{abstract}

Key words: intimate partner violence - women - femicide - Turkey

$$
* * * * *
$$

\section{INTRODUCTION}

Violence against women has increasingly come to be recognized as a major public health concern and a human-rights violation at the international level (Ellsberg et al. 2008, Jewkes et al. 2002, Koenig et al. 2006, Sabri et al. 2016). Violence against women can take many forms and, depending on the type of relationship that is its context and power structures in operation. The murder of women in the context of intimate partner violence represents the most severe form that faced by women (Dobash \& Dobash 2012, Çilingiroğlu \& Erbaydar 2016, Brittany et al. 20018).

Existing documentation suggests that, intimate partner femicide (IPF) constitutes at more than a third of women homicides at global level (Sharps et al. 2001). In Turkey, nearly half of the femicide cases involved intimate partners (Toprak \& Ersoy 2017).

In Turkey as in other parts of the world, many acts of violence contain harmful traditional practices, such as so-called "crimes of honour". Honour killing (HK) is one of the extreme forms of violence against women. Crimes related to the killing of women in the name of honour are change depending on cultural norms, place, time, and practices (Byreshwar 2014). Historically, almost all cultures across the world including contemporary ones, have connived violence against women in the context that men have the "right" to punish women or control their mobility, sexuality and forms of expression. (United Nations Population Fund 2000). Traditionally, the society believes the female has brought dishonour or shame upon the family by engaging in acts that are deemed wrong or inappropriate (Khafagy 2005, Byreshwar 2014). Overall, the concept of honour serves as a mechanism to reinforce a woman's subordinate position and legitimate patriarchy within certain cultures (Baker et al. 1999).

A significant rise has been observed in the occurrence of the HK cases. Every year, it is estimated that at least 5,000 women are murdered in the name of honour around the world (Kljun 2014, United Nations Population Fund 2000). In Turkey, published data on victims of HK are limited (Women in Statistics 2012). Many cases of the HK are considered unreported or/and falsely labelled as suicides or accidents probably due to stigma or socio-cultural structure in Turkey (Cetin 2015).

Notably, the reports produced by women's organizations or the news that appears in the newspapers were the main resources that providing data about HK. It is clear that, the newspaper-based data related to HK are limited due to reporting bias. Nevertheless, the information in newspapers can be very useful sources for examine the cases of the HK (Earl et al. 2004).

The nature and extent of HK in Turkey have been difficult to estimate as information is generated from media reports but not systematically collected by any government agency (Human Right Association 2014). 
However, clear knowledge related to the size and the ruthless outcomes of $\mathrm{HK}$ may serve to shift harmful traditional practices. Given the scarcity and reliability of data on HK in Turkey, the present study focuses on the epidemiological pattern of HK using data collected through newspaper reports in Turkey.

\section{SUBJECTS AND METHODS}

Turkey is one of the most crowded countries in the world. It has a complex socio-cultural structure, which has differences from the Western world and deep differences exist between sub-groups. Despite more than a century of efforts to modernize and integrate with the Western world, social life in Turkey has traditional norms and values that affect the role of women. In Turkey, women's social status directly affected by male dominance structure, which resulting from these patriarchal social forms (Erman 2001).

\section{Study Procedures}

Ethical approval for the study was obtained from the Ethics Committee of Cumhuriyet University with code: 2015-02/26. Data for the study analysis was collected with the content analyses method from newspaper items (completed reports) on the IPF that published between January $1^{\text {st }} 2010$ and December $31^{\text {st }} 2015$. For this purpose, three national daily newspapers, namely, Cumhuriyet, Hürriyet and Milliyet were selected. By means of archive searching on the internet, incidents were selected if they covered the topics of the IPF. For this research, different search terms including "Honour Killing," "Intimate Partner Homicide," "Intimate Violence Deaths," "Intimate Partner Violence and Murder," "Killing and Wife," "Husband and Murder," and "Femicide" were used.

\section{Selection of the sample and coding}

Inclusion criterion in this study was an incident in which an intimate partner (current or former) was clearly accused of the murder of another intimate partner. Exclusion criteria included incident where the femicide victim did not have an intimate partner's involvement with the perpetrator such as a familial, social, or romantic relationship (e.g., strangers). Furthermore, intimate partner events in which there was insufficient information about perpetrators were also excluded.

Stories on the selected newspaper were read and checked by a group of trained final-year medical students who ensured that there were no duplicate stories or no contradictions or discrepancies for the same story. Duplicate reports of the same incident in more than one paper were removed. A spreadsheet was created to document details that could be used for analyses. For all selected incidents in the study, the following variables were coded: relationship between victim and perpetrator, victim demographic information (e.g., age, married or not), potential reason behind attack (e.g., honour, deception, jealousy, and demand for breaking up/divorce), where the femicide incident occurred and method of killing.

\section{Definition of $\mathrm{HK}$}

Whilst there is no overall consensus in the literature regarding the definition of $\mathrm{HK}$, this research used a definition of $\mathrm{HK}$ as the murder of a female family member (who are believed to bring shame on the family through a dishonoured behaviours), whose murder is undertaken by another family member or members as an act of restoring honour to the family (Byreshwar 2014, Gill 2009, Eisner \& Ghuniem 2013, Dorjee et al. 2013, Cooney 2014).

\section{Data analysis}

The original sample for this study contained 1330 femicide cases that published in the newspapers during the period of six years (2010-2015). We estimated the rates of IPF for each year using estimates of Turkey's female population from 2010 to 2015 . Total number of IPF for each year was divided by the respective estimated female populations to determine the rates of IPF per year. Statistical Package of Social Science (SPSS Inc., Chicago, IL) for Windows version 16.0. were used for data analysis. Firstly, all data were exported to SPSS for subsequent data analyses. Then, categorical and quantitative data were expressed as percentages and as mean \pm standard deviation, SD, respectively. Differences in the characteristics between $\mathrm{HK}$ and non- HK were assessed using the chi-square test. Multiple logistic regression analysis was also performed to assess which variables were significantly associated with HK. The analyses reported here assumed simple random sampling for simplicity. HK was entered in the regression model as the dependent variable. Age groups, marital status, relationship between victim and killer and methods of killing were included simultaneously in the model as independent variables. All statistical tests were conducted at the 5\% significance level.

\section{RESULTS}

\section{Distribution of the rate of IPF cases by year}

During the study period from 2010 to 2015 in which the study was conducted, more than 200 women were killed by intimate partner every year. The average overall age of the IPF cases was 34.3 years with a range of 13-75 years. The Table 1 illustrates the rates of IPF cases over a six years period. According to the Table 1, the highest rate of the IPF cases was observed in the year of 2014 while the lowest one was accounted in the year of 2012. 
Table 1. The numbers and rates of intimate femicide victimization by years $(n=1330)$

\begin{tabular}{lcc}
\hline Years & Number & Rate (Per million) \\
\hline 2010 & 214 & 5.8 \\
2011 & 229 & 6.2 \\
2012 & 148 & 3.9 \\
2013 & 198 & 5.2 \\
2014 & 273 & 7.0 \\
2015 & 268 & 6.8 \\
\hline
\end{tabular}

\section{The characteristics of the IPF cases}

The median age of the study population was 36.0 years. As presented in Table 2, The age group in which IPF cases are most common is the group under the age of 36 years $(n=799,60.1 \%)$. Given the marital status, about one-half of the IPF cases were married ( $n=655$, $49.2 \%$ ). Regarding to the relationship between victim and perpetrator, in more than half of the IPF cases, perpetrators were mainly husband or ex-husband $(n=741,55.7 \%)$. Moreover, the most common potential reasons were domestic conflict $(n=472,35.5 \%)$ and the woman's demand to breaking up or divorce ( $n=434,32.6 \%$ ). Also, just over $14 \%$ of the IPF cases $(\mathrm{n}=188)$ has accounted as HK. The most common methods used for killing were firearms $(n=790$, $59.4 \%)$. The next most commonly used method was a sharp objects $(\mathrm{n}=362,27.2 \%)$.
Bivariate analysis results comparing age groups are shown in Table 2. Regarding to age groups, there were differences among the IPF cases in terms of marital status, type of relationship between victim and perpetrator and potential reason for femicide incident. However, there were no significant differences regarding to methods of victim killing. As demonstrated in bivariate analysis, compared to relatively old victims of IPF, relatively young ones were likely to engage in non-marital cohabitation $(31.9 \%$ versus $7.7 \% ; \mathrm{P}<0.001)$ and intended to have a perpetrator as partner or ex-partner $(32.4 \%$ versus $22.2 \%$; $\mathrm{P}<0.001$ ), while domestic conflict as a potential reason for victim was fairly common among relatively old ones (43.9\% versus $29.9 \%$; $\mathrm{P}<0.001)$.

\section{The characteristics of the victims of honour killings}

The characteristics of the victims of HK can be seen in Table 3. During the study period of 6 years, a total of 188 (14.1\% of 1330$)$ victims of HK were recorded. The majority of them were significantly under the age of 36 (74.5\% versus $57.7 \%$; $\mathrm{P}<0.001$ ). Compared to non- HK, the victims of $\mathrm{HK}$ were largely engaged in non-marital cohabitation $(30.9 \%$ versus $20.8 \% ; \mathrm{P}<0.024)$ and their femicide were committed by their relatives $(6.4 \%$ versus $2.3 \%$; $\mathrm{P}<0.001)$ with other methods such as strangulation, hanging, electrocution or poisoning (20.2\% versus $12.3 \%$; $\mathrm{P}<0.001)$ (Table 3).

Table 2. Distribution of characteristics of the study sample by age groups and total sample in Turkey

\begin{tabular}{|c|c|c|c|c|}
\hline \multirow[b]{2}{*}{ Characteristics } & \multicolumn{3}{|c|}{ Age Groups } & \multirow[b]{2}{*}{ Chi-Square Test } \\
\hline & $\begin{array}{l}\text { Total } \\
\mathrm{n}(\%)\end{array}$ & $\begin{array}{c}\text { Under } 36 \\
\text { n }(\%)\end{array}$ & $\begin{array}{c}36 \text { and Above } \\
n(\%)\end{array}$ & \\
\hline Total & $1330(100.0)$ & $799(60.1)$ & $531(39.9)$ & \\
\hline Marital status of the victims & & & & $<0.001$ \\
\hline Married & $655(49.2)$ & $355(44.4)$ & $300(56.5)$ & \\
\hline Non-marital cohabitation & $296(22.3)$ & $255(31.9)$ & $41(7.7)$ & \\
\hline Single* & $379(28.5)$ & $189(23.6)$ & $190(35.8)$ & \\
\hline Relationship between victim and perpetrator & & & & $<0.001$ \\
\hline Husband or ex-husband & $741(55.7)$ & $425(53.2)$ & $316(59.5)$ & \\
\hline Partner or ex- partner & $377(28.3)$ & $259(32.4)$ & $118(22.2)$ & \\
\hline Relative** & $172(12.9)$ & $113(14.2)$ & $59(11.2)$ & \\
\hline Unknown & $40(3.0)$ & $2(0.3)$ & $38(7.2)$ & \\
\hline Potential reason for femicide incident & & & & $<0.001$ \\
\hline Domestic conflict & $472(35.5)$ & $239(29.9)$ & $233(43.9)$ & \\
\hline Demand to breaking up /divorce & $434(32.6)$ & $298(37.3)$ & $136(25.6)$ & \\
\hline Honour & $188(14.1)$ & $140(17.5)$ & $48(9.0)$ & \\
\hline Jealousy & $75(5.6)$ & $31(3.9)$ & $44(8.3)$ & \\
\hline Others $* * *$ & $118(8.9)$ & $75(9.4)$ & $43(8.1)$ & \\
\hline Unknown & $43(3.2)$ & $16(2.0)$ & $27(5.1)$ & \\
\hline Methods of victim killing & & & & 0.478 \\
\hline Firearms & $790(59.4)$ & $468(58.6)$ & $322(60.6)$ & \\
\hline Sharp objects & $362(27.2)$ & $227(28.4)$ & $135(25.4)$ & \\
\hline Others $* * * *$ & $178(13.4)$ & $104(13.0)$ & $74(13.9)$ & \\
\hline
\end{tabular}

* This category includes divorced and/or widowed women; $* *$ This category includes sibling, father, uncle, cousin as well as father-in-law or brother-in-law; $\quad * * *$ This category includes each of following reasons: Psychological criser, blackmail, financial problems, refusal of man's will and rejection; $* * * *$ This category involves each of following methods: Strangulation, hanging, electrocution or poisoning 
Table 3. Baseline characteristics of the femicide cases based on honour killing or not, and total sample in Turkey

\begin{tabular}{lcccc}
\hline Characteristics & $\begin{array}{c}\text { Total } \\
\mathrm{n}(\%)\end{array}$ & $\begin{array}{c}\text { Honour } \\
\mathrm{n}(\%)\end{array}$ & $\begin{array}{c}\text { Others } \\
\mathrm{n}(\%)\end{array}$ & $\begin{array}{c}\text { P value } \\
\text { Chi-Square Test }\end{array}$ \\
\hline Total & $1330(100.0)$ & $188(14.1)$ & $1142(85.9)$ & $<0.001$ \\
Age (In years) & & & & \\
$\quad<36$ & $799(60.1)$ & $140(74.5)$ & $659(57.7)$ & \\
$\quad \geq 36$ & $531(39.9)$ & $48(25.5)$ & $483(42.2)$ & \\
Marital status & & & & \\
$\quad$ Married & $655(49.2)$ & $82(43.6)$ & $573(50.2)$ & \\
$\quad$ Cohabiting & $296(22.3)$ & $58(30.9)$ & $238(20.8)$ & \\
$\quad$ Single* & $379(28.5)$ & $48(25.5)$ & $331(29.0)$ & \\
Closeness to killer & & & & \\
$\quad$ Husband or ex-husband & $741(55.7)$ & $80(42.6)$ & $661(57.9)$ & \\
$\quad$ Partner or ex- partner & $377(28.3)$ & $48(25.5)$ & $329(28.8)$ & \\
$\quad$ Relative** & $172(12.9)$ & $60(34.9)$ & $112(9.8)$ & \\
$\quad$ Unknown & $40(3.1)$ & $0(0.0)$ & $40(3.5)$ & \\
Methods of victim killing & & & & \\
$\quad$ Firearms & $790(59.4)$ & $108(57.5)$ & $682(59.7)$ & \\
$\quad$ Sharp objects & $362(27.2)$ & $42(22.3)$ & $320(28.0)$ & \\
$\quad$ Others*** & $178(13.4)$ & $38(20.2)$ & $140(12.3)$ & \\
\hline
\end{tabular}

* This category includes divorced and/or widowed women; ** This category includes sibling, father, uncle, cousin as well as fatherin-law or brother-in-law; $\quad * * *$ This category involves each of following methods: Strangulation, hanging, electrocution or poisoning.

Table 4. Relation between socio-demographic variables and honour killing in logistic regression analysis, with odds ratios and $95 \%$ confidence intervals $(n=1330)$

\begin{tabular}{lrr}
\hline \multirow{2}{*}{ Independent Variables } & \multicolumn{2}{c}{ Honour killing } \\
& $\beta$ & OR $(95 \% \mathrm{CI})$ \\
\hline Age (In years) & & \\
$\quad<36$ & 1.00 & \\
$\quad \geq 36$ & 0.70 & $2.0(1.39-2.87)$ \\
Marital status & & \\
$\quad$ Married or Single* & 1.00 & \\
$\quad$ Cohabiting & 0.26 & $1.3(0.90-1.88)$ \\
Relationship between victim and killer & \\
$\quad$ Non-Relative & 1.00 & \\
$\quad$ Relative** & 0.20 & $1.2(0.63-2.27)$ \\
Methods of victim killing & & \\
$\quad$ Firearms or sharp objects & 1.00 & \\
$\quad$ Others*** & 0.60 & $1.8(1.20-2.70)$ \\
\hline
\end{tabular}

* This category includes divorced and/or widowed women;

** This category includes sibling, father, uncle, cousin as well as father-in-law or brother-in-law;

*** This category involves each of following methods: Strangulation, hanging, electrocution or poisoning. All statistically significant $P$ values are in italics type.

Variables associated with HK were presented in Table 4. Based on multivariate logistic regression analysis, being at a relatively young age (odds ratio, $\mathrm{OR}=2.0$, $\mathrm{r}=0.70, \mathrm{P}<0.001$ ) was significantly associated with a risk of HK. Also, using other methods such as strangulation, beaten to death and blow to the head were the factor associated with $\mathrm{HK}(\mathrm{OR}=1.8, \mathrm{r}=0.60, \mathrm{P}=0.004)$ (Table 4).

\section{DISCUSSION}

This paper is the first to document the characteristics of honour killing based on the IPF cases in Turkey. This is particularly important given the continued increase in the IPF in Turkey (Table 1). The increase in the number of IPF in Turkey is likely to be related to women's increased ability to leave abusive relationships. Over the past decades, a rapid urbanization process has started to change the traditional social and cultural norms of society in Turkey with modern ones. For example, in addition to their roles as mothers, women's access to and participation in the labour force has increased during this time of change in society (Women in Statistics 2012). As a result of these changes in gender roles and status between husbands and wives in the Turkish society, a woman who failing to live up to traditional norms might easily find herself in conflict with a man who wants to adhere to traditional norms, and such a conflict can cause to death of her. Thus, in Turkey, it can be speculated that the increased rate of the IPF in recent years arises from the direct or indirect effect of the rapid urbanization process on women's new position and men's traditional status (Cetin 2015).

In accordance with previous researches which reported that the peak age for IPF victims were in the range of 30-49 years the median age of the IPF cases in the present study was also placed in the fourth decade (Toprak \& Ersoy 201, Fong et al. 2016, Karbeyaz et al. 2013, Yilmaz et al. 2015). Moreover, previous studies have revealed differences in the age of the IPF cases. In their study of Shackelford and Mouzos (Shackelford \& Mouzos 2005) found that the relatively young age group had a higher number of femicide. Consistent with this finding, in this study, IPF was observed more frequently among younger women (31.9\% versus $7.7 \%)$.

Recent studies from Turkey and other setting indicated that the vast majority of the IPF cases (76\%-80\%) were women whose marriages or relationships have failed (Toprak \& Ersoy 2017, Karbeyaz et al. 2013, Yilmaz et al. 2015, Shackelford \& Mouzos 2005). 
Similarly, the current study revealed that more than $70 \%$ of the IPF cases were women whose marriages or cohabiting have failed, at the time of their deaths. Furthermore, these women mostly were killed by current or ex-partner (32.4\% versus $22.2 \%$ ), (Table 2 ). As demonstrated in the current study, the pattern of the IPF is an unrestricted crime and women who had ever been in some types of intimate partner relationships were more likely to be killed by an intimate partner.

Although true prevalence of HK is unknown, it is reported in numerous countries around the world (Kulczycki \& Windle 2011). In recent studies from Turkey, it has been estimated that $26 \%-48 \%$ of all femicides was committed on infidelity/jealousy/honour or custom-related reasons (Toprak \& Ersoy 2017, Karbeyaz et al. 2013, Yilmaz et al. 2015, Shackelford \& Mouzos 2005). However, these researches did not distinguish between IPF/non-IPF and all IPF incidents were contained in the dataset. This current study demonstrated that $14 \%$ of the IPF incident were committed with honourable reasons, predominately against young woman. The fact that the current study revealed some similarities in the patterns of the HK with types of relationship and age of the victims to contributes to our understanding of $\mathrm{HK}$ within intimate partner relationships. As reported in previous studies, HK is mostly observed in women who older than 18 years (Nasrullah et al. 2009). Moreover, in a current study on $\mathrm{HK}$, it was indicated that majority of the HK cases were between the ages of 18 and 34 (Celbis et al. 2013). In the present study, the average age of the HK cases was 30 years and mostly observed in the ages of less than 36 years.

The literature provides some evidence associated with the risk of the HK based on the different type of interpersonal relationship, especially in the societies where patriarchal strong family ties are maintained (Douki et al. 2003). It was suggested that cohabiting women have a higher risk for HK than married ones (Nasrullah et al. 2009, Fendoğlu 2008). In line with this research the current study's finding demonstrated that non-marital relationships were more common in the HK cases, particularly in relatively young ones. This might be explained by reflects of social, cultural, regional or religious factors of populations where the researches are carried out. For example, in certain countries, cultural killings of women, such as dowry deaths or HK is often not treated as a crime (Sabri et al. 2015).

The HK pattern showed in this research confirms previous studies findings that women who are victims of HK were generally killed by their relatives in accordance with religious and moral norms (Patel \& Gadit 2008). Femicide are most often committed by their husbands or ex-husbands, boyfriends or ex-boyfriend's worldwide; however, what is different for HK's is that multiple close family members such as parents, brothers or cousins are often involved in the killings (Sev'er \& Yurdakul 2001).

An association between age and HK was found in the present study. There was around a 2.0 times greater risk of $\mathrm{HK}$ among younger women, and this finding was consistent with previous research indicating that the majority of the HK cases are committed in the young ages (Nasrullah et al. 2009).

It is likely that the majority of the HK would have been committed by firearms in Turkey, but the fact that other methods such as strangulation, hanging, electrocution or poisoning were used in a significant proportion of the HK cases in the present study. This may be explained by the fact that in order to protect themselves from the justice system, the perpetrators may have shown murders as suicide or accident (Khafagy 2005, Nasrullah et al. 2009).

\section{Strengths and limitations}

The strength of the study is elaborately analysis of data associated with HK based on the IPF reports of newspaper. Such reports in countries such Turkey, where there is a lack of official information about HK, can still provide useful information on HK.

Because of newspapers are an inadequate source for such data as they do not report all such cases and do not systematically report the same information (eg, characteristics of victims and perpetrator) for all cases that they do report, the number of HK in the current study might not represent real number in patterns of femicide, following the argument that cases of the HK are more common in countries such Turkey with low female homicide rates. However, this status might be a result of incomplete homicide data collection system. Information related to intimate femicide is generally derived from police investigation data or from search of judicial records (Karbeyaz et al. 2013). In this case, some murders will remain unsolved for many years or never be solved, but the number of such unsolved cases is mainly dependent on the attitude of the police and the quality of criminal justice system.

\section{CONCLUSION}

The current study documented the potential risks for the HK in Turkey. The rate of femicide has increased during the study period from 2010 to 2015 . The cases of the HK were mostly observed among women at the younger ages.

Assessing the nature and pattern of HK for protecting women from lethal violence will be crucial to find the best effective prevention strategies and programs. Because of the restricted data related to HK, further research is needed to gain a comprehensive understanding of the increased risk for HK using multiple sources of information (e.g., police, mortuaries, medical and judicial records). But that information was not attempted for the current study.

\section{Acknowledgements: None.}

Conflict of interest: None to declare. 


\section{References}

1. Baker NV, Gregware, PR., Cassidy MA: Family killing fields: honour rationales in the murder of women. VAW 1999; 5:164-184

2. Bhanbhro S, Chavez AC, Lusambili A: Honour based violence as a global public health problem: a critical review of literature. Int J Hum Rights Healthc 2016; 9:198-215

3. Brittany EH, Colleen EM, Freilich JD, Chermak SM: Are Honor Killings Unique? A comparison of honor killings, domestic violence homicides, and hate homicides by farright extremists. Homicide Stud 2018; 22:70-93

4. Byreshwar P: "Honour killing" the menace. Indian Journal of Applied Research 2014: 4:259-261

5. Çilingiroğlu N, Erbaydar N: P390 Intimate partner violence: Turkey's femicide problem. Injury Prevention 2016; 22:A143

6. Celbis O, Ozdemir B, Oruc M, Dogan M, Egri M: Evaluation of Honour Killings in Turkey. Med Science 2013; 2:640-8

7. Cetin I: Defining Recent Femicide in Modern Turkey: Revolt Killing. JIWS 2015; 16:346-60

8. Cooney M: Death by family: Honor violence as punishment. Punishm Soc 2014; 16;406-27

9. Dobash RP \& Dobash RE: Who died? The murder of collaterals related to intimate partner conflict. VAW 2012, 18:662-71

10. Douki S, Nacef F, Belhadj A, Bouasker A, Ghachem R: Violence against women in Arab and Islamic countries. Arch Womens Ment Health 2003; 6:165-71

11. Dorjee T, Baig N, Ting-Toomey S: A social ecological perspective on understanding "Honor Killing": An intercultural moral dilemma. J Intercult Commun Res 2013; 42:1-21

12. Earl J, Martin A, McCarthy JD, Soule SA: The use of newspaper data in the study of collective action. Annu Rev Sociol 2004; 30:65-80

13. Eisner $M$ \& Ghuniem L: Honor killing attitudes amongst adolescents in Amman, Jordan. Aggress Behav 2013; 39:405-17

14. Ellsberg M, Jansen HA, Heise L, Garcia-Moreno C: Intimate partner violence and women's physical and mental health in the WHO multi-country study on women's health and domestic violence: an observational study. Lancet 2008; 371:1165-72

15. Erman T: Rural migrants and patriarchy in Turkish cities. Int J Urban Reg Res 2001; 25:118-33

16. Fendoğlu HT: PM Human Rights Presidency 2007 Honour Killings Report. Ankara, 2008. Available from: https://rojwomen.files.wordpress.com/2010/05/honour killings report by govt 2007.pdf. Accessed in 2018 (Jun 27)

17. Human Right Association, 2014

18. Fong WL, Pan CH, Lee JC, Lee TT, Hwa HL: Adult femicide victims in forensic autopsy in Taiwan: A 10-year retrospective study. Forensic Sci Int 2016; 266:80-5
19. Jewkes R, Levin J, Penn-Kekana L: Risk factors for domestic violence: findings from a South African crosssectional study. Soc Sci Med 2002;55:1603-17

20. Karbeyaz K, Akkaya H, Balci Y: An analysis of the murder of women in a 10-year period in Eskissehir province located in western Anatolia in Turkey. J Forensic Leg Med 2013; 20:736-9

21. Khafagy F: Honour killing in Egypt. Cairo, UN Division for the Advancement of Women, 2005. Available from: http://www.un.org/womenwatch/egm/vaw-gp-2005/docs/ experts/khafagy.honorcrimes.pdf. Accessed in 2018 (Jun 27)

22. Kljun S: In the name of honour. Bulletin (Law Society of South Australia), 2014; 36:18-19

23. Kulczycki $A$ \& Windle S: Honor Killings in the Middle East and North Africa a systematic review of the literature. VAW 2011; 17:1442-64

24. Koenig MA, Stephenson R, Ahmed S, Jejeebhoy SJ, Campbell J: Individual and contextual determinants of domestic violence in North India. Am J Public Health 2006; 96:132-8

25. Nasrullah M, Haqqi S, Cummings KJ: The epidemiological patterns of honour killing of women in Pakistan. Eur J Public Health 2009; 19:193-7

26. Patel $S$ \& Gadit AM: Karo-kari: A Form of Honour Killing in Pakistan. Transcult Psychiatry 2008; 45:683-94

27. Sabri B, Sanchez MV, Campbell JC: Motives and characteristics of domestic violence homicides and suicides among women in India. Health Care Women Int 2015; 36:851-66

28. Sabri B, Campbell JC, Dabby FC: Gender differences in intimate partner homicides among ethnic sub-groups of Asians. VAW 2016; 22:432-53

29. Sev'er A \& Yurdakul G: Culture of honor, culture of change a feminist analysis of honor killings in rural Turkey. VAW 2001; 7:964-98

30. Shackelford TD \& Mouzos J: Partner killing by men in cohabiting and marital relationships: A comparative, cross-national analysis of data from Australia and the United States. J Interpers Violence 2005; 20:1310-24

31. Sharps PW, Koziol-McLain J, Campbell J, McFarlane J, Sachs $C, X u X$ : Health care providers' missed opportunities for preventing femicide. Prev Med 2001; 33:373-80

32. Toprak $S$ \& Ersoy G: Femicide in Turkey between 2000 and 2010. PLoS One 2017; 12:e0182409

33. United Nations Population Fund: Lives together, worlds apart: men and women in a time of change. The State of World Population, 2000; 25-30. Retrieved from: www.unfpa.org/sites/default/files/pub-pdf/swp2000_eng.pdf

34. Women in Statistics 2012. Publication Number: 3904, Ankara: Turkish Statistics Institution; 2012. Available from: http://esitizberaberiz.org/wp-content/uploads/2014/02/ TU\%C4\%B0statistiklerle-Kad\%C4\%B1n-2012.pdf. Accessed in 2018 (Jun)

35. Yilmaz E, Kumral B, Canturk N, Erkol Z, Okumus AM: Analysis and comparison of domestic femicide cases in the cities of Diyarbakir \& Tekirdag, Turkey: A preliminary study. J Forensic Leg Med 2015; 34:17-23

Correspondence:

Prof. Naim Nur, MD

Department of Public Health, School of Medicine, Sivas Cumhuriyet University

58140 Sivas, Turkey

E-mail:naimnur@yahoo.com 